\title{
Effect of Systematic Desensitization and Cognitive Restructuring on English Speaking Anxiety
}

\author{
L.H. Chen \& D.M. Wang \\ Dalian University of Technology, Dalian, China
}

\begin{abstract}
Anxiety is a major factor that influences the effectiveness of public speaking. This paper examined how a 16-week classroom instruction on English public speaking that includes systematic desensitization and cognitive restructuring training affects public speaking anxiety for Chinese non-English major college students. The results prove that systematic desensitization and cognitive restructuring are significantly effective to reduce students' English public speaking anxiety.
\end{abstract}

KEYWORD: Systematic Desensitization; Cognitive Restructuring; English Public Speaking Anxiety

\section{INTRODUCTION}

To college students, English speaking is not only an effective way to practice English expression ability, but also an important means to promote comprehensive qualities, enhance confidence and develop critical thinking ability. More and more college students are keen on courses about English speaking. However, studies show that varying levels of physiological and psychological anxiety reactions such as blushing, sweating, rapid heartbeat, eyes dodge, legs trembling, voice trembling, stutter, confusion of thinking occur to most speakers before and during their speech in public places. Serious anxiety reactions will not only directly influence the speech effect, but also lead to a negative evaluation of the speaker himself/herself which would cause even more serious physiological and thinking anxiety symptoms, and form a loop amplification effect of the speech anxiety reactions. Therefore, apart from the speaking skills instruction in English speaking classes, teachers should also help students to learn their anxiety situation and effective methods to relieve it. It will make the students more confident, promote their English expression ability and give full play to the role of English speaking in improving the ability of language communication, increasing English learning interest and promoting comprehensive qualities.

\section{BACKGROUND}

\subsection{Public speaking anxiety}

Public speaking anxiety, one form of oral communication apprehension, is one of the specific symptoms of non-extensive social anxiety disorder. It refers to the physiological and psychological anxiety reactions occur to the speaker during his/her public speech (Brydon \&Scott 2006). McCroskey (1976) believes that every speaker experiences more or less anxiety related to the speech situation. For some individuals, anxiety is so debilitating that it interferes with interpersonal (McCroskey et al. 1975, 1976), academic and vocational success (McCroskey \& Andersen 1976). And studies in recent years show that students who are learning English as a second or additional language suffer even more English speaking anxiety (Alemi et al. 2011). Some scholars are calling for teachers and course designers to adopt more classroom activities to help students relieve their speaking anxiety (Awan et al. 2010).

In China, studies on English speaking anxiety mainly converged in the last six years. In 2009, researchers analyzed the causes of English speaking anxiety. Jin Shuangjun (2009) held the point that among main causes of speaking anxiety such as selfconcept, personality, speaking elements preparation and knowledge base, self-concept and speaking elements preparation exert the largest impact on speech anxiety level. Zhang Fang (2009) focused on the analysis of the causes of contestants' anxiety in English speaking contests. Later, more researchers tried to adopt a variety of methods to help students relieve English speaking anxiety. Liu Li (2011) conducted an empirical research on cognitivebehavioral group treatment; Jin Shuangjun (2011) believed that learners training will help students reduce their speaking anxiety. Zhang Fang (2010, 2011) made an attempt with both group counseling 
intervention and video feedback method; $\mathrm{Yu} \mathrm{Li}$ (2013), on the other hand, adopted classroom activities to reduce students' anxiety by helping them develop confidence.

\subsection{Systematic desensitization and cognitive restructuring}

Systematic desensitization is a widely used technology in treating fear and anxiety generated by a particular stimulus. It induces people who are seeking treatment to gradually expose to the situations that cause neurotic anxiety and fear. Then a relaxed mental state will be adopted against them, and the goal of eliminating the anxiety or fear will be eventually achieved. The process of systematic desensitization is to gradually increase the level of stimulation. Once a stimulus doesn't cause the anxiety and terror response of the person who is seeking treatment any more, the treatment implementer may present a stronger stimulus to the person who is seeking treatment while he/she is in a relaxed state. If the anxiety and terror state presented by the treatment implementer is within the tolerance of him/her, he/she will not feel the anxiety and terror of the stimulus after repeated presentation. And then, the treatment goal is achieved.

Cognitive restructuring is a process of changing belief system. As a psychological treatment technology, it aims at helping individuals who have emotional problems recognize improper, distorted and maladaptive beliefs, and replace them with proper, accurate and well-adjusted beliefs. REBT (Rational Emotive Behavior Therapy), a typical technique of realizing cognitive restructuring is put forward in 1950's by Albert Ellis, an American psychologist. According to this technique, the root of emotional apprehension is irrational beliefs, and to develop coping statement for each irrational belief is the way to cure emotional problems.

How to apply systematic desensitization and cognitive restructuring, two widely used specific technologies in psychotherapy area, to the foreign language classroom teaching, and develop them into foreign language anxiety control technologies? Domestic researchers have made initial attempts in recent years: Wang Tianjian (2011) gave a detailed introduction about helping students keep relaxed in various threatening situations by using systematic desensitization, that is, relaxation and imagination training, and realizing cognitive reconstruction of students suffer from foreign language anxiety through the following four steps: (1) helping students understand rational and irrational beliefs (2) helping students identify the rationality and irrationality of different beliefs (3) helping students identify the impact that different beliefs have on learning (4) helping students monitor and change irrational beliefs and their accompanying reactions.
Shi Yu and Fan Weiwei (2012) explored the impacts that systematic desensitization and cognitive restructuring have on students' foreign language listening anxiety and foreign language listening ability, and conducted an in-depth discussion on how these impacts are generated.

In the context of the above research, with nonEnglish major college students as the research object, and English speaking classroom teaching practice as the foundation, this paper explores the mitigation of students' English speaking anxiety after the classroom instruction of systematic desensitization and cognitive restructuring training.

\section{METHOD}

\subsection{Participants}

Participants consist of 124 sophomores at a key university in Liaoning Province in China. 64 of them were placed in Class 01 (C01) and got trained on systematic desensitization and cognitive restructuring, while 60 of them were in Class 02 (C02) and had no such training during a 16-week course of English public speaking. Both classes were taught by the same lecturer.

\subsection{Data}

The data of the study came from the results of two instruments. One is PRCS (Personal Report of Confidence as a Speaker). PRCS scale is used to measure speaking anxiety, evaluate the emotional experience and behavioral responses of the speaker when he/she is giving public speech or statement. The scale contains 30 topics, which is answered with "Yes" or "No" and scored with " 0 " or " 1 ". In order to control the convergence effect during the answering, there are "positive" and "negative" entries which are equal in amounts arranged in the scale. The total score of the scale is 30 . Higher score represents higher anxiety. The other instrument is learners' diary. Students are required to record their attitude, concept and introspection of the treatment during the process of systematic desensitization and cognitive restructuring training which lasts for one semester.

\subsection{Procedures}

\subsubsection{Systematic desensitization training}

Systematic desensitization training is conducted in the following four steps: (1) list anxiety situations. List specific situational stimuli that cause individual English speaking anxiety reactions, that is, write down every situation that has caused or may cause your anxiety as detailed as possible. (2) rank anxiety level. Rank different individual anxiety reactions into "anxiety level" from the lowest to the highest. 
Put the weakest stimulus, that is, the situation that causes nearly no anxiety or very little anxiety at the first place and list all the rest situations in order. (Table 1 is an example). The bigger the number, the more anxiety the situation will cause. (3) form a relaxation response through relaxation training. Close your eyes and do some muscle relaxation exercises, until all the muscles can enter a relaxed state quickly. (4) imagine the anxiety situation in a relaxed state. Imagine the first situation on the above anxiety stimulus level list, if feel anxious, take tens of seconds to do some muscle relaxation exercises. Then imagine the same situation again, until the anxious feelings go away. And then imagine the second stimulus situation. Such exercise takes about 15 minutes each time.

Table 1. List of situational stimuli that cause public speaking anxiety.

\begin{tabular}{|l|l|}
\hline 1 & I have to write four speeches in this semester. \\
\hline 2 & I have difficulty in writing my speech. \\
\hline 3 & $\begin{array}{l}\text { I found others were all better than me when I was } \\
\text { listening to their speeches. }\end{array}$ \\
\hline 4 & $\begin{array}{l}\text { The computer breaks down and I can't use visual aids I } \\
\text { have prepared. }\end{array}$ \\
\hline 5 & Audiences are snickering during my speech. \\
\hline 6 & I am asked to deliver an impromptu speech. \\
\hline 7 & I dry up in the midst of my speech. \\
\hline 8 & $\begin{array}{l}\text { Nothing comes to my mind at all when I stand on the } \\
\text { stage. }\end{array}$ \\
\hline
\end{tabular}

\subsubsection{Cognitive restructuring training}

Cognitive restructuring training mainly contains the following three aspects:

(1)Reorganize irrational beliefs and rational beliefs

Irrational beliefs are rigid, unreasonable beliefs which lead to negative emotions and behaviors. Students' most common irrational beliefs are excessive demands and self-deprecation. (For example: I have to give a perfect performance in this speech and win the applause of all my classmates; I must get a high score in this speech; I forget my words twice during this speech, I am so stupid; my voice is always so rigid, people like me are not meant to be a speaker. ) Rational beliefs are flexible and reasonable beliefs which lead to positive emotions and behaviors. For example, a fervent hope (I really hope to perform well in this speech, but I don't have to) and self-affirmation (even though I forgot my words twice in this speech, I attracted the attention of the audience with vivid content and clear logic, I did a good job.). After every speech, students are required to list all their irrational beliefs in it (from the preparation to the completeness) and convert them into rational beliefs.

(2) Recognize the impact that different beliefs have on learning

Tell students that language learners who have irrational beliefs tend to force themselves to reach certain goals and believe that failures will lower individual values. They usually experience excessive foreign language anxiety. Anxiety will lower the efficiency of learning and lead to escape behavior, and eventually cause school failure. On the other hand, language learners who have rational beliefs will get enough motivation with their fervent hope. They have less anxiety about disagreeable results and will not experience excessive anxiety in their foreign language learning, hence get higher learning efficiency. They tend to brave participation and active practice in the foreign language classroom and eventually achieve success in foreign language learning.

(3) Help students monitor and change irrational beliefs and their accompanying reactions

Students' irrational beliefs and their accompanying emotions and behaviors have been existed for a long time and most of them have already been fixed. When adopting REBT treatment for cognitive reconstruction, teachers should help students to "grasp" and control these beliefs, emotions and reactions intentionally. STEB

( Situation; Thought; Emotion; Behavior) model provides effective monitoring technology. Students can monitor their irrational beliefs through introspection. For example: S: a spontaneous speech; $\mathrm{T}$ : must be smooth and brilliant; E: nervous and anxious; B: afraid of actively raising their hands and stepping onto the stage to give a speech. Once these irrational thoughts and behaviors are recognized, they can be intentionally changed. Students should continue to establish reasonable, active and positive rational beliefs and make them confident and brave with the change of beliefs. Then they will actively participate in classroom activities and truly carry out the cognitive reconstruction.

\section{RESULTS}

On the paired-samples t-test comparing the pre-test and post-test of participants from $\mathrm{C} 01$ and $\mathrm{C} 02$ respectively, we can see significant difference between the pre-test and post-test of participants from C01 $(p=.000)$, while not for the participants from $\mathrm{C} 02(p=.009)$. This result means that after getting trained on systematic desensitization and cognitive restructuring, $\mathrm{C} 01$ participants have much lower speech anxiety, while with no training on systematic desensitization and cognitive restructuring, C02 participants' anxiety almost stays the same (see Table 2).

On the independent-samples t-test comparing the pre-test from $\mathrm{C} 01$ and $\mathrm{C} 02$, there was no significant difference on anxiety of participants from $\mathrm{C} 01$ and $\mathrm{C} 02$ ( $p=.503)$. On the independent-samples t-test comparing the post-test from $\mathrm{C} 01$ and $\mathrm{C} 02$, we 
found significant difference on anxiety of participants from $\mathrm{C} 01$ and $\mathrm{C} 02(p=.000)$. This indicates that training on systematic desensitization and cognitive restructuring helps reducing participants' speech anxiety (see Table 3 ).

Table 2. Paired-samples t-test for participants from $\mathrm{C} 01$ and $\mathrm{C} 02$.

\begin{tabular}{|c|c|c|c|c|c|c|c|}
\hline & \multirow{2}{*}{$\mathrm{N}$} & \multicolumn{2}{|c|}{ Pre-test } & \multicolumn{2}{|c|}{ Post-test } & \multirow{2}{*}{$t$} & \multirow{2}{*}{$p$} \\
\cline { 3 - 6 } & & Mean & $\mathrm{SD}$ & Mean & $\mathrm{SD}$ & & \\
\hline $\mathrm{C} 01$ & 64 & 18.75 & 4.305 & 13.06 & 4.059 & 5.302 & .000 \\
\hline $\mathrm{C} 02$ & 60 & 18.13 & 4.925 & 17.60 & 4.427 & 2.692 & .009 \\
\hline
\end{tabular}

Table 3. Independent-samples t-test comparing pre-test and post-test of participants.

\begin{tabular}{|c|c|c|c|c|c|c|}
\hline & $\mathrm{C} 01$ & \multirow{2}{*}{$\mathrm{N}$} & $\mathrm{C} 02$ & \multirow{2}{*}{$\mathrm{N}$} & $t$ & $p$ \\
\cline { 2 - 4 } & $\mathrm{Mean}(\mathrm{SD})$ & & $\mathrm{Mean}(\mathrm{SD})$ & & & \\
\hline Pre-test & $\begin{array}{c}18.70 \\
(4.288)\end{array}$ & 60 & $\begin{array}{c}18.13 \\
(4.925)\end{array}$ & 60 & -6.077 & .000 \\
\hline Post-test & $\begin{array}{c}12.98 \\
(3.877)\end{array}$ & 60 & $\begin{array}{c}17.60 \\
(4.427)\end{array}$ & 60 & .672 & .503 \\
\hline
\end{tabular}

\section{CONCLUSIONS}

According to the experimental data, it is obvious that speaking anxiety of the experimental class shows a significant reduction after the experiment, which means systematic desensitization and cognitive restructuring training can effectively help students alleviate speaking anxiety. With the help of learners' diary, we find that after repeated relaxation training; most of the students who scored more than 16 in the PRCS scale before the experiment have gradually relieved their anxiety about certain situations that cause speaking anxiety. Students' speaking anxiety has been effectively reduced by adaptation to the anxious situations and control of anxious emotions. Also, there are a lot of students who have intentionally changed their irrational learning concept during the cognitive reconstruction training, found the reasonable position of their speaking images and established their confidence of speaking. When negative subconscious emotions are replaced by positive ones, students' anxious physiological symptoms during their speech such as blushing, sweaty palms and trembling legs will disappear.

English speaking is a challenge to college students' comprehensive qualities and abilities. A robust psychological quality is the precondition of a good English speech, which provides assistance and protection for the play of language skills and performing skills. This study aims at English speaking anxiety of non-English major college students, achieves some positive results through intervention of systematic desensitization and cognitive restructuring training. However, due to the fact that the amount of the sample of the study is small, the measurement results and psychological intervention effects still need further verification.

\section{REFERENCES}

[1] Alemi, M., Daftarifard, P., \& Pashmforoosh, R. 2011. The Impact of Language Anxiety and Language Proficiency on WTC in EFL Context. Cross-Cultural Communication (7): 150-166.

[2] Awan, R., Azher, M., Anwar, M. N., \& Naz, A. 2010. An Investigation of Foreign Language Classroom Anxiety and Its Relationship with Students' Achievement. Journal of College Teaching and Learning (7): 33-40.

[3] Ayers, J. 1988. Coping with Speech Anxiety: The Power of Positive Thinking. Communication Education (37): 289-296.

[4] Ayers, J. 1990. Situational Factors and Audience Anxiety. Communication Education (39): 283-291.

[5] Brydon, S.R. \& Scott, M.D (eds.). 2006. Between One and Many: The Art and Science of Public Speaking (3rd Ed.). Mountain View. CA: Mayfield Publishing Co.

[6] Ellis, A. 2004. Rational Emotive Behavior Therapy: It Works for Me -It Can Work for You. Amherst. NY: Prometheus.

[7] Jin, Shuangjun. 2009. College students' English speaking anxiety and its causes. Chinese Journal of Medical Education Research (11): 1432-1434.

[8] Jin, Shuangjun. 2011. Effect of learner's training on reducing speaking anxiety. Foreign Language World (2):28-35.

[9] Liu, Li. 2011. A case study on Chinese students' English speaking anxiety. Journal of Basic English Education (4): 32-35.

[10] McCroskey, J.C. \& Andersen, J.F. 1976. The relationship between communication apprehension and academic achievement among college students. Human Communication Research (3): 73-81.

[11] McCroskey, J.C. \& Richmond, V.P. 1976. The effects of communication apprehension on the perception of peers. Western Speech Communication (40): 14-21.

[12] Shi, Yu \& Fan, Weiwei. 2012. Systematic desensitization and cognitive restructuring: study on reducing college student's listening anxiety. Foreign Language Education (0): 64-72.

[13] Wang, Tianjian. 2011. Systematic desensitization and cognitive restructuring - control strategies on high school students' English anxiety. Journal of Teaching and Management (5):47- 49.

[14] Wu, Xiaomei. 2002. Systematic desensitization. Psychology and Health (6):61-65.

[15] Yang, li. 2009. The intervention of cognitive behavior group therapy on public speaking anxiety. Journal of Hubei University of Chinese Medicine (4): 61-63.

[16] Yu, Li. 2013 Study on reducing Chinese college students' English speaking anxiety. Course Education Research (6): 87-91.

[17] Zhang, Fang. 2009. Causes and therapy for college students' English speaking contest anxiety. Journal of Qiqihar Vocational College (9): 35-37.

[18] Zhang, Fang. 2010. Non-English majors' speaking anxiety and psychological intervention. Journal of Shenyang Institute of Engineering (4): 259-261.

[19] Zhang, Fang. 2011. Function of "Video Feedback" on reducing college students' English speaking anxiety. Journal of Language and Literature Studies (8): 153-154 